\title{
Randomized clinical trial comparing different iodine interventions in school children
}

\author{
Jinkou Zhao ${ }^{1, *}$, Fujie Xu ${ }^{2}$, Qinlan Zhang ${ }^{1}$, Li Shang ${ }^{1}$, Aixiang Xu ${ }^{3}$, Yuan Gao ${ }^{3}$, \\ Zhigao Chen ${ }^{1}$, Kevin M Sullivan ${ }^{2}$ and Glen F Maberly ${ }^{4}$ \\ 'Jiangsu Provincial Center for Public Health and Diseases Control, Nanjing, China: \\ ${ }^{2}$ Department of Epidemiology, Rollins School of Public Health, Emory University, Atlanta, USA: \\ ${ }^{3}$ Nanjing Institute of Schistosomiasis Control, Nanjing, China: ${ }^{4}$ Department of International Health, \\ Rollins School of Public health, Emory University, Atlanta, USA
}

Submitted 11 September 1998: Accepted 25 January 1999

\begin{abstract}
Objective: The purpose of this trial was to compare three different iodine interventions.

Design: School children aged 8-10 years were randomized into one of three groups: group A was provided with iodized salt by researchers with an iodine concentration of 25 ppm; group B purchased iodized salt from the market; and group C was similar to group $\mathrm{B}$ with the exception that they were given iodized oil capsules containing $400 \mathrm{mg}$ iodine at the beginning of the study. Salt iodine content was measured bimonthly for 18 months and indicators of iodine deficiency were measured at baseline and 6, 9, 12 and 18 months after randomization.

Results: The prevalence of abnormal thyroid volumes, based on the World Health Organization (WHO) body surface area reference $>97$ th percentile, was $18 \%$ at baseline and declined to less than $5 \%$ by 12 months in groups A and C, and to $9 \%$ after 18 months in group B. Results for goitre by palpation were similar. The median urinary iodine was $94 \mu \mathrm{gl}^{-1}$ at baseline and increased in all groups to $>200 \mu \mathrm{g} \mathrm{l}{ }^{-1}$ at the 6-month follow-up.

Conclusions: In this population of school children with initially a low to moderate level of iodine deficiency, the group receiving salt with $25 \mathrm{ppm}$ (group A) was not iodine deficient on all indicators after 18 months of study. When the iodine content of the salt varied, such as in group B, by 18 months thyroid sizes had not yet achieved normal status.
\end{abstract}

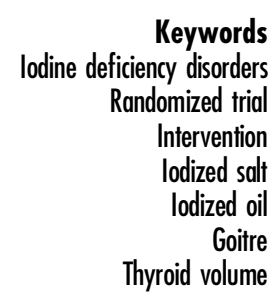

Iodine deficiency is the leading preventable cause of brain damage and mental retardation worldwide ${ }^{1}$. The consequences of iodine deficiency, collectively referred to as iodine deficiency disorders (IDD), include cretinism, mental retardation, goitre, abortion, stillbirths, congenital anomalies and low birth weight ${ }^{2}$. In 1990 it was estimated that 655 million people worldwide had goitre and 1.6 billion are at risk of IDD $^{1}$. The elimination of IDD by the year 2000 was determined to be a global public health priority at the 'World Summit for Children' in $1990^{3}$. Over this decade, the elimination of iodine deficiency through national salt iodization programmes has been a global development priority. Most national programmes use the prevalence of goitre in school children as their main indicator to evaluate programme success. The prevalence of goitre has not declined as rapidly as expected in some areas and sometimes it is inconsistent with urinary iodine results.

IDD is a significant public health problem in China ${ }^{1}$. A national survey in 1995 found the prevalence of goitre among school children to be $\geqslant 10 \%$ in 27 of 30 provinces ${ }^{4}$. The present study was performed in Jiangsu Province which was classified in 1995 as having a mild level of IDD $^{5}$ according to WHO/UNICEF/ICCIDD criteria with a total goitre rate (TGR) in school children of $17 \%$ and median urinary iodine levels of $85 \mu \mathrm{gl}^{-1}$.

The primary intervention used to prevent IDD has been the iodization of salt, which has been associated with the successful elimination of IDD in a number of countries ${ }^{6}$. Currently it is recommended that salt be iodized in the range of $20-40 \mathrm{ppm}$ at the point of production in order to assure that median urinary iodine levels are in the $100-200 \mu \mathrm{gl}^{-1}$ range $^{7}$. UNICEF estimates that nearly $60 \%$ of all edible salt in the world is currently iodized ${ }^{8}$. If iodized salt is not available in an iodine-deficient area, iodized oil capsules are frequently distributed. An oral dose of $400 \mathrm{mg}$ iodized oil may maintain a median level of iodine in the urine of $>100 \mu \mathrm{g} \mathrm{l}^{-1}$ for 12 months $^{9,10}$.

Following the introduction of iodized salt into an iodine-deficient population, there has been little 
information on how long it takes for thyroids, which increase in size as a consequence of the deficiency, to return to normal size. The importance of this question is because the prevalence of goitre and abnormal thyroid volumes in school children are used as an indicator of the magnitude of IDD. Many countries are now observing a persistence of goitre in school children despite apparent successful implementation of near universal iodized salt consumption. This randomized clinical trial was performed to determine the impact of iodized salt and iodized oil on thyroid size and urinary iodine in school children in a remote population during an 18-month period.

\section{Methods}

\section{Study population}

This study was performed on Baguanzhou Island, Jiangsu Province, China. This island, located on the Yangzi River with a ferry connection to the mainland, has a population of 30000 and covers an area of approximately $47.8 \mathrm{~km}^{2}$. Agriculture is the principal occupation and most foods consumed are grown locally. Prior to the present study there were no data on the iodine status of the population nor had an iodine prophylaxis programme been initiated on this island. Salt distributed in the area had not been iodized prior to the present study.

Sample size was estimated based on the following conditions: the prevalence of goitre or abnormal thyroid volume at baseline would be $25 \%$ and after 18 months, would be 5\%; an alpha value of 0.05 ; and a power of $80 \%$. Given these conditions, 60 children in each group would be required. The sample size was increased to allow for loss to follow-up and because the prevalence at baseline was not known with accuracy.

Households of pupils in grades $2-4$ in Baguanzhou Elementary School were invited to participate voluntarily in the study. Pupils who were less than 8 years of age were excluded from the study.

\section{Intervention and outcome measures}

Pupils were allocated into one of three groups using systematic block randomization based on age and sex (Fig. 1): pupils in group A were provided with iodized salt specifically produced to contain $25 \mathrm{ppm}$ ( $42.25 \mathrm{~g}$ of potassium iodate per kilogram of salt). Homogeneity, consistency and precise iodine concentration of the salt were achieved by thorough mixing and close laboratory monitoring. Every 2 months, researchers distributed the iodized salt to their households immediately after production and collected salt left over from the previous distribution. Pupils in group B purchased commercially available salt in the market. Pupils in group C were similar to group B except that they received four capsules of iodized oil, each containing $100 \mathrm{mg}$ iodine, at the start of the study. The iodized oil used in this trial was provided by Wuhan Fourth Pharmaceuticals Factory (Wuhan, China), in which iodine was bound to unsaturated fatty acids from poppy seed oil ${ }^{11}$. All salt used for the study, both the specially prepared salt for group A and the salt commercially available in the market, was supplied by one producer (Xiaguan Salt Company, Nanjing, China).

The three populations were followed for 18 months. Salt samples were tested for their iodine content using the titration method described by Sullivan et al. ${ }^{12}$. Starting at the second month of the study, every 2 months until the end of study, pupils brought salt samples from their homes for iodine detection. At baseline and 6, 9, 12 and 18 months after randomization, palpation and thyroid ultrasonography were performed, and height, weight and urine samples were obtained. Thyroid volume was measured using real-time ultrasonography which was performed by one experienced physician using portable ultrasound equipment with a $7.5 \mathrm{MHz}$ linear array transducer (AKHO, Inc, Canada). Longitudinal and transverse scans were performed allowing the measurement of the depth $(d)$, the width $(w)$ and the length $(l)$ of each lobe in centimetres. The volume of each lobe was calculated by the formula: volume $(\mathrm{ml})=0.479 \times d \times$ $w \times l$ and the thyroid volume estimated as the sum of both lobes. Thyroid volume was classified as normal or abnormal using the thyroid volume for body surface area (BSA) reference described by Delange et $a l .{ }^{13}$. BSA was calculated by using the formula: BSA $\left(\mathrm{m}^{2}\right)=W^{0.425} \times H^{0.725} \times 71.84 \times 10^{-4}$ where $W$ is the child's weight in kilograms and $H$ the child's height in centimetres ${ }^{14}$. The prevalence of abnormal thyroid volume (ATV) was calculated as the number of children with a volume above the upper limit ( $>97$ th percentile) divided by the total number of children measured.

Casual urine samples were collected using bottles processed with heavy acids and washed with demineralized water several times before collecting urine samples to avoid contamination. The urinary iodine concentrations were analysed within 24 hours using a modified acid-digestion method in the Jiangsu Province iodine laboratory ${ }^{15}$, which is under regular quality control by the Chinese Academy of Preventive Medicine and Chinese National Institute of IDD. Urinary iodine analysis of six blind quality assurance samples at three levels by the Jiangsu Province laboratory did not demonstrate bias compared to the true values $(P=0.14)$. The precision of these determinations is $2.4 \%$. (Laboratory quality assurance results can be found in the Appendix.)

All laboratory tests (salt titration and urinary iodine analyses) and thyroid size determinations (palpation 


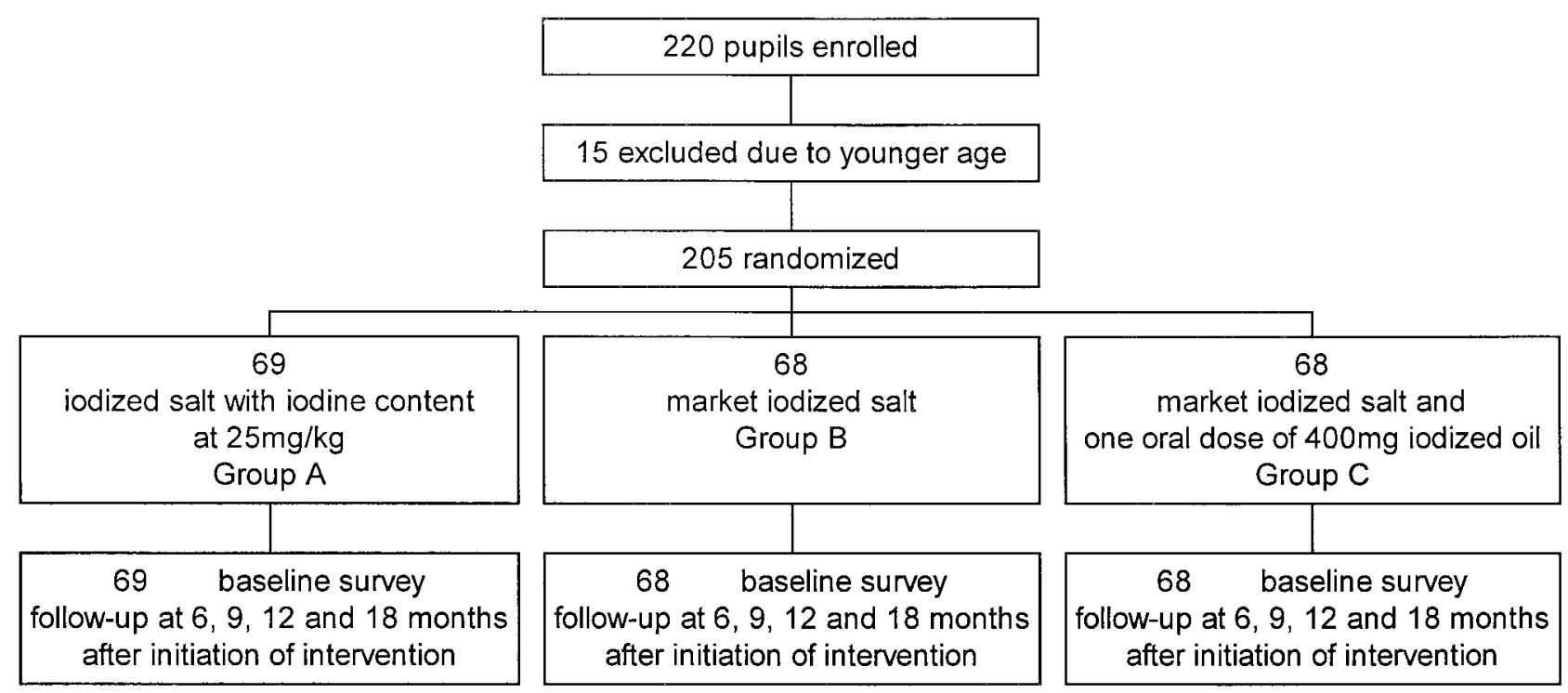

Fig. 1 Trial profile

and ultrasonography) were performed without knowledge into which group the pupils had been randomized.

\section{Data analysis}

Criteria by WHO/UNICEF/ICCIDD were used to classify the severity of IDD in the population ${ }^{16}$. For thyroid volumes and goitre, the classification is based on the prevalence of the condition: mild, 5-19.9\%; moderate, 20-29.9\%; and severe, $\geqslant 30 \%$. For the median urinary iodine, the classification is: mild, 50$99 \mu \mathrm{gl}^{-1}$; moderate, 20-49 $\mu \mathrm{gl}^{-1}$; and severe, $<20 \mu \mathrm{g} \mathrm{l}{ }^{-1}$.

Data were analysed with Epi Info 6.04 and SAS 6.12. Confidence intervals for median values were calculated as described by Campbell and Gardner ${ }^{17}$. Confidence intervals for the prevalence of ATV and TGR are based on the exact binomial method. The differences in ranking of the urinary iodine distributions were tested using the Kruskal-Wallis method. Chi-square tests were applied to compare the TGR and the prevalence of ATV over time among groups.

\section{Results}

Of the 220 pupils enrolled in grades 2-4, 205 were 810 years of age and were randomized into one of the three groups (Fig. 1). All households agreed to voluntarily participate in the study and there were no withdrawals during the 18-month study period. The number of urinary iodine results available varied at each follow-up visit, from 130 (63\%) to 149 (73\%) out of the 205 pupils followed. The three groups did not differ in age, sex, weight, height, BSA, TGR, prevalence of ATV, or median urinary iodine at baseline (Table 1). Approximately half of the pupils were male, TGR was $27 \%$, the prevalence of ATV 18\%, and the median urinary iodine in all three groups was $<100 \mu \mathrm{gl}^{-1}$. Using the $\mathrm{WHO} / \mathrm{UNICEF} / \mathrm{ICCIDD}$ classifications ${ }^{16}$, the

Table 1 Comparison of general variables among three groups at the beginning of the study

\begin{tabular}{|c|c|c|c|c|}
\hline Variables & Group A & Group B & Group C & $P$ value* \\
\hline \multicolumn{5}{|l|}{ Number of pupils: } \\
\hline aged 8 years & 23 & 22 & 23 & \\
\hline aged 9 years & 23 & 24 & 22 & \\
\hline aged 10 years & 23 & 22 & 23 & 0.996 \\
\hline total & 69 & 68 & 68 & \\
\hline Sex: male (\%) & 50.7 & 50.0 & 50.0 & 0.995 \\
\hline Weight (mean, kg) & 28.0 & 28.1 & 28.0 & 0.990 \\
\hline Height (mean, cm) & 129.3 & 129.1 & 129.2 & 0.983 \\
\hline Body surface area (mean, $\mathrm{m}^{2}$ ) & 1.002 & 1.004 & 1.003 & 0.959 \\
\hline Total goitre rate $(\%)$ & 26.1 & 26.5 & 26.5 & 0.998 \\
\hline Prevalence of abnormal thyroid volume (\%) & 17.4 & 17.7 & 17.7 & 0.999 \\
\hline Median urinary iodine $\left(\mu \mathrm{gl}^{-1}\right)$ & 92.4 & 95.0 & 94.2 & 0.828 \\
\hline
\end{tabular}

${ }^{*}$ Chi-square test was used for comparison for proportion of age, sex, total goitre rate and the prevalence of abnormal thyroid volume. One-way ANOVA was used for comparison for the mean weight, mean height, mean body surface area and mean thyroid volume. The Kruskal-Wallis method was used to compare the median urinary iodine concentration. 

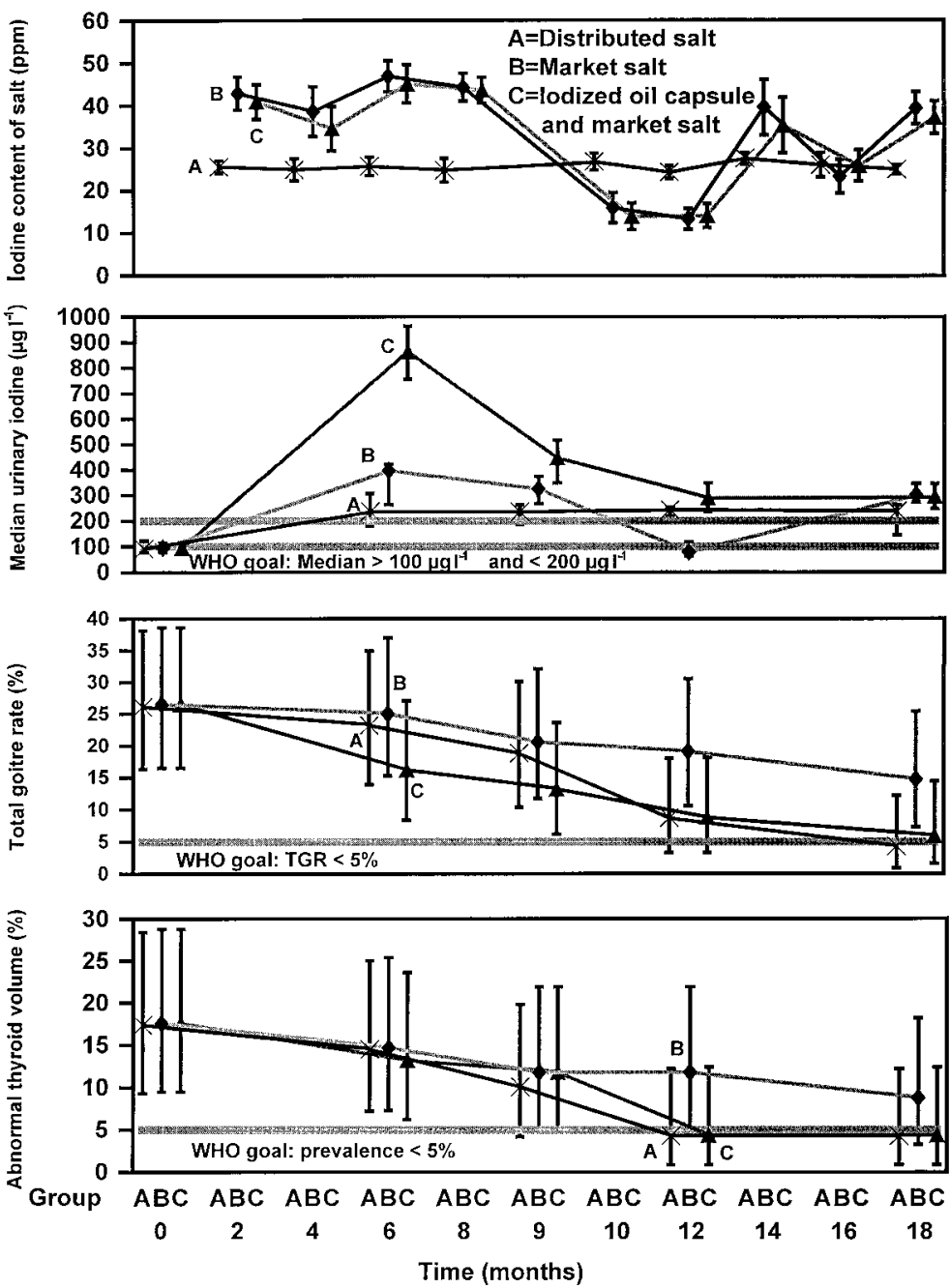

Fig. 2 lodine content of salt, median urinary iodine levels, total goitre rate and the prevalence of abnormal thyroid volume by group over time. Error bars represent $95 \%$ confidence intervals

TGR would classify the area as having a moderate level of IDD, and the levels of prevalence of ATV and median urinary iodine would classify the area as having a mild level of IDD.

The salt iodine content in group A was stable with mean values ranging from 24 to 28 ppm during the study period. For groups $\mathrm{B}$ and $\mathrm{C}$, the iodine concentrations in the salt varied, with mean values from 13 to 47 ppm (Fig. 2). No significant difference in mean salt iodine concentrations was found between groups $\mathrm{B}$ and $\mathrm{C}(P>0.05)$, but the mean salt iodine content in group A differed significantly from groups $\mathrm{B}$ and $\mathrm{C}(P<0.01)$.

At baseline all three groups had a median urinary iodine $<100 \mu \mathrm{gl}^{-1}$ and at all subsequent visits the urinary iodine was $>200 \mu \mathrm{gl}^{-1}$ with one exception (Fig. 2). In group $B$ the urinary iodine fell below $100 \mu \mathrm{gl}^{-1}$ at the 12-month follow-up, which corresponds to the time when the iodine content of the market salt fell below 16 ppm (months 10 and 12). After the iodine content of the market salt remained $>23 \mathrm{ppm}$ at months 14-18, the median urinary iodine level increased in group $\mathrm{B}$. When the iodine content of the market salt was $>25$ ppm, group B had a higher median urinary iodine level than group $\mathrm{A}$; when the iodine content of the market salt fell below 25 ppm, group A had a higher urinary iodine level than group B. As would be expected, the median urinary iodine at month 6 was the greatest in pupils who received the iodized oil capsules. Significant differences in median urinary iodine levels were found among the three groups $(P<0.001)$ at $6,9,12$ and 18 months.

In all three groups, the prevalence of ATV and TGR declined during the study period (Fig. 2). By the 12th month, groups A and $\mathrm{C}$ had a prevalence of ATV $<5 \%$, and a TGR near $5 \%$ by the 18 th month. For group B, the prevalence of ATV declined similarly to groups A and $\mathrm{C}$ until between months 9 and 12, where there 
was little decline. This corresponds to the same time when the iodine content of the market salt fell below $16 \mathrm{ppm}$.

\section{Discussion}

Based on the results in group A, one of the main findings in this study was that consumption of salt with a uniform iodine content of $25 \mathrm{ppm}$ maintained a urinary iodine level $>100 \mu \mathrm{gl}^{-1}$ and reduced thyroid sizes to normal levels after 12-18 months. In a population where the salt iodine concentration is not consistently maintained to at least $20 \mathrm{ppm}$ in the household, it may take longer for thyroid sizes to return to normal, as with group $\mathrm{B}$. The latter situation is more likely to be found in the real world, as many salt producers have not established stringent quality assurance to guarantee a uniform and standard concentration of iodine at the household level. In group C, the addition of iodized oil capsules as well as iodized salt from the market gave similar beneficial results to those seen in group A after 12-18 months. In populations with severe levels of IDD, it is likely that the prevalence of ATV and TGR may take longer to become normal.

In the study population, the severity of IDD based on the WHO/UNICEF/ICCIDD criteria for urinary iodine, goitre, and ATV indicated a mild or moderate level of IDD prior to intervention ${ }^{16}$. Six months after the initiation of the study, for group A the urinary iodine values indicated no IDD whereas goitre and thyroid ultrasound still indicated a mild to moderate level of IDD. It is biologically plausible that as the iodine intake increases, this will be reflected within days in the excretion of iodine in the urine, but it takes months, and perhaps years, for the thyroid size to return to normal, at least in an initially mildly to moderately deficient population. After 18 months, in groups A and $\mathrm{C}$, all three IDD indicators were in agreement in indicating no IDD. In group B, after 18 months the urinary iodine indicated no IDD while the TGR and the prevalence of ATV indicated mild IDD. When there are inconsistencies between different indicators of IDD, where frequently urinary iodine is normal but thyroid size indicates IDD, this may be due to an inadequate amount of time allowed for the population to attain a low prevalence of goitre after initiation of the intervention. Another possible explanation for differences between indicators could be the accuracy of the urinary iodine analyses and assessment of thyroid size.

A concern with the introduction of iodized salt into populations with moderate to severe levels of IDD is the potential for the occurrence of iodine-induced hyperthyroidism $(\mathrm{IIH})^{18}$. To minimize the potential of $\mathrm{IIH}$, it has been recommended that the iodine content of salt be set at the minimal level to result in median urinary iodine levels in the $100-200 \mu \mathrm{gl}^{-1}$ range. In group A, it appears that the iodine content of the salt could be decreased slightly while still ensuring iodine sufficiency. In group B, the iodine content of the salt varied widely during the study period indicating potentially poor quality control by the producer. When the iodine content of the salt in the household for group B was $>38 \mathrm{ppm}$ the urinary iodine levels were much higher than $200 \mu \mathrm{gl} l^{-1}$, and when the iodine content was $<15 \mathrm{ppm}$ the urinary iodine level fell below $100 \mu \mathrm{gl}^{-1}$.

Because of the limited sample size, the power to detect some differences between groups was not high. While the confidence intervals around the salt iodine content and urinary iodine levels were relatively narrow, the confidence intervals around the prevalence of ATV and TGR were wide.

At baseline, the median urinary iodine levels and ATV indicated 'mild' IDD while the TGR indicated 'moderate' IDD. The WHO/UNICEF/ICCIDD cut-offs are not exact, and slight discrepancies may be expected. Other possible explanations for the slight differences include that the individual performing the palpation may have overestimated the prevalence or that the urinary iodine results may be higher than in other laboratories. Concerning the comparison of ATV and TGR, the WHO thyroid volume for BSA reference is relatively new and, as of this writing, there was no published literature comparing these two methods.

Compared to group $\mathrm{B}$, the urinary iodine concentration in group $\mathrm{C}$ was about $450 \mu \mathrm{gl}^{-1}$ higher, which is consistent with results of studies using the same iodized oil capsules ${ }^{11}$, and remained higher until 12 months. This indicates that oral administration of $400 \mathrm{mg}$ of iodized oil can be effective for the first 12 months. This result is similar to a number of studies ${ }^{9,10,19-21}$ and in contrast with others ${ }^{22,23}$. A literature review failed to find any studies reporting the simultaneous effects of iodized salt and iodized oil. The raised median urinary iodine concentration in group $\mathrm{C}$ in the first 12 months could be the combined effects of iodized oil and iodized salt.

It is recommended that all salt for human and animal consumption be adequately iodized to eliminate IDD. The iodine content of the salt should ideally result in urinary iodine levels in the $100-200 \mu \mathrm{gl}^{-1}$ level $^{7}$. In many situations this requires iodizing the salt at between 20 and $40 \mathrm{ppm}$ at the factory. The exact level at which to iodize salt depends on a number of factors, including the amount of iodine from other sources, the average salt consumption per person per day, the methods used to add iodine to salt, and other factors that lead to iodine loss between production and consumption. It is important for salt producers and public health officials to work together to ensure 
that iodized salt is produced with high and consistent quality and that its impact on the population is monitored to ensure that the iodine intake of the population is neither too low nor too high.

\section{Acknowledgements}

This study was supported by the Office for Endemic Diseases Control, Jiangsu Provincial Government. The authors thank the personnel involved in the data collection, data entry and laboratory analyses; the principal and teachers of Baguanzhou Elementary School; and the families and pupils for their participation in the study.

\section{References}

1 WHO/UNICEF/ICCIDD. Global Prevalence of Iodine Deficiency Disorders. Micronutrient Deficiency Information System Working Paper No. 1. Geneva: WHO, 1991.

2 Delange $F$. The disorders induced by iodine deficiency. Thyroid 1994; 4(1): 107-28.

3 UNICEF. First Call for Children: World Declaration and Plan of Action from the World Summit for Children. New York: UNICEF, 1990.

4 Comprehensive Evaluation and Planning Mission. Report of the Mission's Observations and Recommendations, Program of International Cooperation for the Elimination of IDD in China by the Year 2000. Program Against Micronutrient Malnutrition, Atlanta, USA, 1-15 July 1996.

5 Zhao JK, Gu SD, Yang XX. Current status of IDD in Jiangsu Province. Chin. J. Endem. Dis. Control 1997; 12(4a): 129-32.

6 Van der Haar F. Salt iodization in the control of iodine deficiency: increasing the cooperation among government, industry and science. Seventh Symposium on Salt 1993; 2: 421-6.

7 WHO/UNICEF/ICCIDD Joint Consultation. Review of Findings from a Seven-Country Study in Africa on Levels of Salt Iodization in Relation to Iodine Deficiency Disorders, Including Iodine-induced Hyperthyroidism. WHO/NUT/ 97.2. Geneva: WHO, 1997.

8 UNICEF. The State of the World's Children 1998. New York: Oxford University Press, 1998: 54-5, 64.

9 Benmiloud M, Chaouki ML, Gutekunst R, Teichert HM, Wood WG, Dunn JT. Oral iodized oil for correcting iodine deficiency: optimal dosing and outcome indicator selection. J. Clin. Endocrinol. Metab. 1994; 79: 20-4.

10 Bautista A, Barker PA, Dunn JT, Sanchez M, Kaiser DL. The effects of oral iodized oil on the intelligence, thyroid status, and somatic growth in school-age children from an area of endemic goiter. Am. J. Clin. Nutr. 1982; 35: 127-34.

11 Anon. The effect of oral administration of iodized oil for prevention and treatment of endemic goiter. Chin. Med.J. 1981; 61(9): 533-4.
12 Sullivan KM, Houston R, Gorstein J, Cervinskas J. Monitoring Universal Salt Iodization Programmes. Atlanta: PAMM/MI/ ICCIDD, 1995: 86-7.

13 Delange F, Benker G, Caron P et al. Thyroid volume and urinary iodine in European schoolchildren: standardization of values for assessment of iodine deficiency. Eur. J. Endocrinol. 1997; 136: 180-7.

14 Dubois D, Dubois EF. Clinical calorimetry: a formula to estimate the approximate surface area if height and weight be known. Arch. Intern. Med. 1916; 17: 863.

15 Dunn JT, Crutchfield HE, Gutekunst R, Dunn AD. Two simple methods for measuring iodine in urine. Thyroid 1993 ; 3: 119-23.

16 WHO/UNICEF/ICCIDD Joint Consultation. Indicators for Assessing Iodine Deficiency Disorders and their Control through Salt Iodization. WHO/NUT/94.6. Geneva: WHO, 1994.

17 Campbell MJ, Gardner MJ. Calculating confidence intervals for some non-parametric analyses. In: Gardner MJ, Altman GD, eds. Statistics with Confidence: Confidence Intervals and Statistical Guidelines. London: British Medical Journal, 1995: 72-4

18 Stanbury JB, Ermans AE, Bourdoux P et al. Iodine-induced hyperthyroidism: occurrence and epidemiology. Thyroid 1998; 8(1): 83-100.

19 Tonglet R, Bourdoux P, Minga T, Ermans AM. Efficacy of low doses of iodized oil in the control of iodine deficiency in Zaire. N. Engl.J. Med. 1992; 326(4): 236-41.

20 Elnagar B, Eltom M, Karlsson FA, Ermans AM, GebreMedhin M, Bourdoux PP. The effects of different doses of oral iodized oil on goiter size, urinary iodine, and thyroid-related hormones. J. Clin. Endocrinol. Metab. 1995; 80(3): 891-7.

21 Abuye C, Hailemariam B, Tibeb HN, Urga K, Gebru H The effect of varying doses of oral iodized oil in the prophylaxis of endemic goiter in elementary schools children. Ethiop. Med. J. 1995; 33(2): 115-23.

22 Ingenbleek Y, Jung L, Ferard G, Bordet F, Goncalves AM, Dechoux L. Iodized rapeseed oil for eradication of severe endemic goiter. Lancet 1997; 350: 1542-5.

23 Furnee CA, Pfann GA, West CE, van der Haar F, van der Heide D, Hautvast JG. New model for describing urinary iodine excretion: its use for comparing different oral preparations of iodized oil. Am. J. Clin. Nutr. 1995; 61(6): $1257-62$.

\section{Appendix}

All quality assurance specimens were tested three times with the results shown below.

\begin{tabular}{lcc}
\hline $\begin{array}{l}\text { No. of } \\
\text { specimen }\end{array}$ & $\begin{array}{c}\text { True value } \\
\left(\mu \mathrm{g} \mathrm{I}^{-1}\right)\end{array}$ & $\begin{array}{c}\text { Mean of measured values } \\
\left(\mu \mathrm{g} \mathrm{I}^{-1}\right)^{*}\end{array}$ \\
\hline 1 & 76.3 & $79.4(78.9,79.7,79.6)$ \\
2 & 153.9 & $159.1(157.6,158.6,161.2)$ \\
3 & 296.3 & $297.4(295.4,296.8,300.1)$ \\
$\mathrm{I} 1$ & 89.4 & $91.1(89.8,91.6,92.0)$ \\
$\mathrm{I} 2$ & 133.0 & $132.7(131.9,132.8,133.4)$ \\
$\mathrm{I} 3$ & 184.9 & $192.7(193.6,191.4,193.1)$ \\
\hline
\end{tabular}

${ }^{*}$ Numbers in parentheses are measured values. 